\title{
Participation in the Journey to Life Conversation Map Improves Control of Hypertension, Diabetes, and Hypercholesterolemia
}

\author{
Paul Crawford, MD, and Scott Wiltz, MD, MPH
}

Background: The Diabetes Conversation Map program includes 4 "board game-like" education tools. We describe how the Journey to Life Conversation Map Education Class improves diabetes performance measures of hemoglobin $\mathrm{A}_{1 \mathrm{c}}\left(\mathrm{HbA}_{1 \mathrm{c}}\right)$, low-density lipoprotein (LDL), and blood pressure (BP).

Methods: Retrospective case-control study in a military family medicine clinic from January 2007 to January 2010. We included 202 patients who completed $\geq 1$ conversation map class and a comparison group of 209 patients who did not attend.

Results: Attendees started with $\mathrm{HbA}_{1 \mathrm{c}} 8.25$ (95\% confidence interval [CI], 7.86-8.64) and decreased to $6.96(95 \% \mathrm{CI}, 6.69-7.23)$. Patients in the comparison group started at $8.57(95 \% \mathrm{CI}, 8.18-8.95)$ and decreased to 8.27 (95\% CI, 8.01-8.54) $(P<.001)$. Attendees began with LDL of $111 \mathrm{mg} / \mathrm{dL}(95 \% \mathrm{CI}$, 103-119) and decreased to $94 \mathrm{mg} / \mathrm{dL}(95 \% \mathrm{CI}, \mathrm{81}-106)$. Patients in the comparison group started at 89 $\mathrm{mg} / \mathrm{dL}(95 \% \mathrm{CI}, 81-98)$ and increased to $98 \mathrm{mg} / \mathrm{dL}(95 \% \mathrm{CI}, 85-110)(P<.007)$. Systolic BP decreased $5.4 \mathrm{mmHg}$ among attendees versus $0.8 \mathrm{mmHg}$ among those in the comparison group $(P=.014)$, whereas diastolic BP was unchanged $(P=.110)$.

Conclusion: The Journey to Life Healthy Interactions Conversation Map Education Class for diabetes improves diabetes performance measures. (J Am Board Fam Med 2015;28:767-771.)

Keywords: Diabetes Mellitus; Education, Patient; Process Assessment (Health Care); Self Care

Approximately 24 million people in the United States have type 2 diabetes (T2DM), which accounts for $95 \%$ of all diabetes cases and becomes more common with increasing age. It is also one of the leading causes of morbidity and mortality worldwide. The American Diabetes Association issues guidelines for T2DM treatment goals for hemoglobin $\mathrm{A}_{1 \mathrm{C}}\left(\mathrm{HbA}_{1 \mathrm{c}}\right)$, low-density lipoprotein (LDL), and blood pressure (BP). ${ }^{1} \mathrm{~A}$ recent large meta-analysis found that lifestyle interventions reduced $\mathrm{HbA}_{1 \mathrm{c}}$ by $0.37 \%$, with $<1-\mathrm{mmHg}$ changes in both systolic BP (SBP) and diastolic BP (DBP).

This article was externally peer reviewed.

Submitted 6 May 2014; revised 19 April 2015; accepted 29 April 2015.

From the Nellis Family Medicine Residency, Nellis Air Force Base, NV.

Funding: Partial funding for project provided by the AFMSA/SG9 Fuchsia Program.

Conflict of interest: none declared.

Corresponding author: Paul Crawford, MD, Nellis Family Medicine Residency, 99MDOS/SGOF, 4700 Las Vegas Blvd N, Nellis AFB, NV 89191 (E-mail: paul.crawford@us.af. mil).
No difference was found in either LDL cholesterol or high-density lipoprotein (HDL) cholesterol. ${ }^{2}$

Some groups (eg, veterans) are more likely to engage in self-care activities. ${ }^{3}$ Education groups can also give valuable sources of social support and provide a tool for patients to achieve treatment goals. $^{4,5}$ Conversation Map content is based on current clinical practice guidelines that represent optimal intervention approaches and applicable standards for a diabetes-specific self-management education. The content was reviewed for clinical accuracy by the American Diabetes Association, International Diabetes Federation, and Diabetes UK. Using 6 components, including a visual map, conversation questions, discussion cards, group interaction, facilitation, and an action plan, the overall purpose of the group visit was to empower individuals with diabetes to take responsibility for their own health and well-being. Each map, a laminated 3-by-5-foot table-top visual with colorful drawings as metaphors of situations familiar to people with diabetes, is placed on a table with partici- 
pants seated around it. Map 1 provides an overview of diabetes and is designed to debunk common myths and encourage discussion of feelings associated with having the disease. Map 2 focuses on the relationship between diabetes and food and includes strategies for healthy eating. Map 3 highlights the importance of monitoring blood glucose and using the results to manage diabetes. Map 4 describes the natural course of diabetes and stresses the potential long-term complications of the disease, including ways to delay or reduce risks. ${ }^{6,7} \mathrm{We}$ describe how the Journey To Life Conversation Map Education Class improves diabetes performance measures of $\mathrm{HbA}_{1 \mathrm{c}}$, LDL, and BP.

\section{Methods}

We conducted a retrospective, case-control trial using electronic records from the Mike O'Callaghan Federal Medical Center, Nellis Air Force Base, Nevada. Patients were included in the study cohort in 2 ways: (1) the case group comprised patients with T2DM who enrolled in the Journey to Life Conversation Map Class for Diabetes between January 2007 and January 2010; (2) the comparison group included patients with T2DM who received usual diabetes care. A total of 2314 patients with diabetes receiving continuous care at our facility who were not enrolled in the Journey to Life Conversation Map Class were ranked by age (years). Then, the first sex-matched person for each age was chosen from the control group as a comparison (eg, a 56-year-old man was in the intervention group, so we scrolled the sheet until we found the first 56-year-old male not already in the study). All potential patients had $\geq 1$ documented clinic visit within the 120 days before enrollment in the class. We excluded patients who had no laboratory or BP evaluations within the 120 days before their first class. We compared laboratory results that were reported between 50 and 180 days after the last class attended and imputed missing values using the carry-forward method. Comparison patients had T2DM and were age- and sex-matched to case patients. The institutional review board of the 59th Medical Wing, Wilford Hall Ambulatory Surgical Center, approved the protocol. Informed consent was waived with approval.

\section{Baseline Data Collection}

Demographic data (age, sex, race); smoking status; medication history (antidiabetes medications, anti- hypertensive medications, lipid-lowering drugs); clinical parameters (height, weight, SBP, and DBP); and laboratory parameters (fasting glucose, $\mathrm{HbA}_{1 \mathrm{c}}$, total cholesterol, LDL cholesterol, HDL cholesterol, triglycerides) were collected. Body mass index was calculated.

\section{Intervention Details}

Conversation Map content is based on current clinical practice guidelines that represent optimal intervention approaches and applicable standards for a diabetes-specific self-management education. The American Diabetes Association, International Diabetes Federation, and Diabetes UK reviewed the content for clinical accuracy.

The Conversation Map tools align with adult learning principles and learner-centered approaches: the information is simple and practical, directed by participant interests, leverages participant experiences, and focuses on application. A learner-centered approach provides opportunities for a learner not just to acquire new information but also to seek its meaning.

The Diabetes Conversation Map as taught included 4 different Conversation Map education tools that focused on topics related to diabetes and diabetes management: (1) overview of diabetes, (2) healthy eating, (3) monitoring and using your results, and (4) natural course of diabetes (http:// educator.journeyforcontrol.com/diabetes_educator/ conversation_map/). Subjects attended group sessions that ranged in size from 4 to 10 participants (average, 5 participants). Classes were held either on Tuesday afternoons at 5:00 p.m. or on Saturday mornings at 9:00 a.m. Registered nurses (with no special certification) led these 2-hour sessions. Using a different map at each session, the subject moved their "game piece" to various locations on the Conversation Map that were important to them, and then the nurses facilitated conversations about those various diabetes-related topics. Classes were held in the family medicine residency clinic in a patient education room, and nurses used various props such as food packaging, media articles, and posters demonstrating proper food portions. No biometric or patient care data were collected during the visits. We provided four 2-hour sessions over a 4-week period (patients were expected to attend 1 session/week), with groups of participants using 1 of 4 different Conversation Map visuals at each visit. 
Table 1. Baseline Characteristics of the Journey to Life Conversation Map Attendee and Comparison Cohorts from January 2007 to January 2010

\begin{tabular}{lccr}
\hline & $\begin{array}{c}\text { Attendee } \\
\text { Cohort }\end{array}$ & $\begin{array}{c}\text { Comparison } \\
\text { Cohort }\end{array}$ & $P$ Value* \\
\hline Age (years) & $59.0 \pm 8.3$ & $58.8 \pm 8.3$ & \\
Sex & & & \\
$\quad$ Female & 54.3 & 54.3 & \\
$\quad$ Male & 45.7 & 45.7 & \\
$\mathrm{HbA}_{1 \mathrm{c}}(\%)$ & $8.25 \pm 2.3$ & $8.57 \pm 1.8$ & $<.001$ \\
$\mathrm{LDL}(\mathrm{mg} / \mathrm{dL})$ & $111.0 \pm 42.5$ & $89.5 \pm 38.3$ & .152 \\
$\mathrm{SBP}(\mathrm{mmHg})$ & $135.1 \pm 16.8$ & $135.5 \pm 17.9$ & .056 \\
$\mathrm{DBP}(\mathrm{mmHg})$ & $81.6 \pm 13.2$ & $78.6 \pm 11.7$ & .048 \\
\hline
\end{tabular}

Values are means \pm standard deviations or percentages.

${ }^{*} P$ values are between groups, calculated using the paired $t$ test. $\mathrm{DBP}$, diastolic blood pressure; $\mathrm{HbA}_{1 \mathrm{c}}$, hemoglobin $\mathrm{A}_{1 \mathrm{c}}$; LDL, low-density lipoprotein; SBP, systolic blood pressure.

\section{Cobort Summary}

Participants entered the study cohort in an open fashion through standard physician referrals. The time origin for the study was completion of 1 Journey to Life class. The time metric was 180 days following completion of an individual's last class. No patients were removed from the cohort. Comparison patients were not offered the opportunity to participate.

\section{Statistical Analysis}

Baseline characteristics of the study cohort and comparison cohort are expressed as numbers (percentages) for categorical variables and as means \pm standard deviations for continuous variables. Continuous and categorical variables first were compared between the study cohort and the comparison group using the Student $t$ test and $\chi^{2}$ test, as appropriate.

For the combination of comparison patients and attendees, repeated-measures analysis of variance with 2 levels of repeated factor (time, before and after) and 2 levels of nonrepeated factor (attendee and comparison). In this analysis the 3 effects were time, group, and an interaction of group and time.

\section{Results}

Baseline characteristics of the class attendee and comparison groups were similar, with no significant differences in age, sex, SBP, or LDL. DBP and $\mathrm{HbA}_{1 \mathrm{c}}$ did show a statistically significant difference despite very small numeric differences at baseline (Table 1). After-class measurements were taken an average of 168 days after completion of the class.

The comparison group showed no significant differences in SBP $(P=.615)$, LDL $(P=.289)$, or $\mathrm{HbA}_{1 \mathrm{c}}(P=.125)$ over time. The comparison group showed a significant decrease in diastolic BP $(P=.007)$ over time. The class attendee group had statistically significant changes in all measured values over time: SBP $(P<.001)$, DBP $(P<.001)$, LDL $(P=.001)$, and $\mathrm{HbA}_{1 \mathrm{c}}(P<.001)$ (Table 2$)$.

When comparing changes between groups over time using analysis of variance, the class attendee group showed significant changes in $\operatorname{SBP}(P=.014)$, LDL $(P=.006)$, and $\mathrm{HbA}_{1 \mathrm{c}}(p=<0.001)$ compared with the comparison group (Table 2). No significant changes in DBP were found $(P=.110)$.

\section{Discussion}

$\mathrm{HbA}_{1 \mathrm{c}}, \mathrm{SBP}$, and LDL were reduced to American Diabetes Association goals in effect at the time of the intervention ${ }^{1}$ among subjects who attended the Journey to Life Diabetes Conversation Map class. This stood in contrast to the comparison group, whose values remained similar.

Different modalities and programs to educate patients abound. Evidence for their effectiveness is varied. Some programs show no long-term benefit

Table 2. Change in Diabetes Disease Parameters in the Journey to Life Conversation Map Attendee and Comparison Cohorts Over Time

\begin{tabular}{lcrr}
\hline & Attendee Cohort (Before/After) & Comparison Cohort (Before/After) & $P$ Value* \\
\hline $\mathrm{HbA}_{1 \mathrm{c}}(\%)$ & $8.25 \pm 2.3 / 6.96+1.4$ & $8.57 \pm 1.8 / 8.27 \pm 1.5$ & $<.001$ \\
$\mathrm{LDL}(\mathrm{mg} / \mathrm{dL})$ & $111.0 \pm 42.5 / 93.7 \pm 71.6$ & $89.5 \pm 38.3 / 97.5 \pm 74.3$ & .006 \\
$\mathrm{SBP}(\mathrm{mmHg})$ & $135.1 \pm 16.8 / 129.8 \pm 15.1$ & $135.5 \pm 17.9 / 134.7 \pm 17.7$ & .014 \\
$\mathrm{DBP}(\mathrm{mmHg})$ & $81.6 \pm 13.2 / 77.4 \pm 11.3$ & $78.6 \pm 11.7 / 76.4 \pm 12.4$ & .110 \\
\hline
\end{tabular}

Values are means \pm standard deviations.

$P$ values are calculated by analysis of variance comparing changes between groups across 2 time periods.

$\mathrm{DBP}$, diastolic blood pressure; $\mathrm{HbA}_{1 \mathrm{c}}$, hemoglobin $\mathrm{A}_{1 \mathrm{c}}$; LDL, low-density lipoprotein; $\mathrm{SBP}$, systolic blood pressure. 
from education (Khunti), whereas others show benefit. ${ }^{8,9}$ Computer-based diabetes self-management interventions currently have limited effectiveness and reduce $\mathrm{HbA}_{1 \mathrm{c}}$ by about $0.2 \%$; mobile phone users have a total reduction of $0.5 \% .^{10,11}$ Perhaps the largest downside to nearly all interventions is that they measure disease-oriented, not patientoriented, evidence and then follow performance measures only for a relatively short period. Hansen et $\mathrm{al}^{12}$ followed subjects for 19 years and found no difference in all-cause mortality.

Diabetes education can be effective in many age groups and with many educational modalities. Older individuals had $\mathrm{HbA}_{1 \mathrm{c}}$ reductions of $0.5 \% .{ }^{13}$ Culturally appropriate education is effective in both short- and medium-term performance measures $\left(\mathrm{HbA}_{1 \mathrm{c}}\right.$ reduced by $0.4 \%$ and $0.5 \%$, respectively). ${ }^{14,15}$ Neither LDL nor HDL was lowered in these interventions.

The largest limitation of this study is its retrospective nature. There is no way to definitively say that the intervention is the only reason that performance measures improved. We did attempt to control for some of the variables by choosing an ageand sex-matched comparison cohort, but variables such as number of medications and number of clinic visits were not collected. In addition, while performance measures were measured for a total of 6 months, the long-term benefit on $\mathrm{HbA}_{1 \mathrm{c}}$, lipids, and BP is unknown.

\section{Conclusion}

While this study was performed in a system where costs to subjects were zero, the simplicity, fun atmosphere, and relatively short 4-session duration of the intervention make it generalizable to many different practice settings. In addition, the 1.1point reduction in $\mathrm{HbA}_{1 \mathrm{c}}$ is comparable to expected reductions from metformin therapy ${ }^{16}$; thus, in some patients, drug therapy may be delayed with this intervention. In addition, while current guidelines still encourage prescription of statin medications as well as angiotensin-converting enzyme inhibitors for most patients with diabetes, values of both LDL and SBP were lower in the intervention group.

Maharaj Singh provided statistical support. Kirsten Verkamp, $\mathrm{RN}$, provided leadership of the education program.

\section{References}

1. American Diabetes Association. Standards of medical care in diabetes-2012. Diabetes Care 2012; 35(Suppl 1):S11-63.

2. Chen L, Pei JH, Kuang J, et al. Effect of lifestyle intervention in patients with type 2 diabetes: a metaanalysis. Metabolism 2015;64:338-47.

3. Lynch CP, Strom JL, Egede LE. Variation in quality of care indicators for diabetes in a national sample of veterans and non-veterans. Diabetes Technol Ther 2010;12:785-90.

4. Belgrave FZ, Lewis DM. The role of social support in compliance and other health behaviors for African Americans with chronic illnesses. J Health Soc Policy 1994;5:55-68.

5. Nathan DM, Buse JB, Davidson MB, et al; American Diabetes Association; European Association for the Study of Diabetes. Medical management of hyperglycemia in type 2 diabetes: a consensus algorithm for the initiation and adjustment of therapy: a consensus statement of the American Diabetes Association and the European Association for the Study of Diabetes. Diabetes Care 2009;32: 193-203.

6. Fernandes OD, Von Worley A, Sperl-Hillen J, Beaton SJ, Lavin-Tompkins J, Glasrud P. Educator experience with the U.S. Diabetes Conversation Map® Education Program in the Journey for Control of Diabetes: the IDEA Study. Diabetes Spectr 2010;23: 194-8.

7. Reaney M, Eichorst B, Gorman P. From acorns to oak trees: the development and theoretical underpinnings of diabetes Conversation Map education tools. Diabetes Spectr 2012;25:111-6.

8. Krebs JD, Parry-Strong A, Gamble E, et al. A structured, group-based diabetes self-management education (DSME) programme for people, families and whanau with type 2 diabetes (T2DM) in New Zealand: an observational study. Prim Care Diabetes 2013;7:151-8.

9. Jessee BT, Rutledge CM. Effectiveness of nurse practitioner coordinated team group visits for type 2 diabetes in medically underserved Appalachia. J Am Acad Nurse Pract 2012;24:735-43.

10. Pal K, Eastwood SV, Michie S, et al. Computerbased diabetes self-management interventions for adults with type 2 diabetes mellitus. Cochrane Database Syst Rev 2013;3:CD008776.

11. Pereira K, Phillips B, Johnson C, Vorderstrasse A. Internet delivered diabetes self-management education: a review. Diabetes Technol Ther 2015;17: 55-63.

12. Hansen LJ, Siersma V, Beck-Nielsen H, de Fine Olivarius N. Structured personal care of type 2 diabetes: a 19 year follow-up of the study Diabetes Care in General Practice (DCGP). Diabetologia 2013;56: 1243-53. 
13. Thongsai S, Youjaiyen M. The long-term impact of education on diabetes for older people: a systematic review. Glob J Health Sci 2013;5:30-9.

14. Attridge M, Creamer J, Ramsden M, Cannings-John R, Hawthorne K. Culturally appropriate health education for people in ethnic minority groups with type 2 diabetes mellitus. Cochrane Database Syst Rev 2014;9:CD006424.

15. Dube L, Van den Broucke S, Housiaux M, Dhoore W, Rendall-Mkosi K. Type 2 diabetes self-manage- ment education programs in high and low mortality developing countries: a systematic review. Diabetes Educ 2015;41:69-85.

16. González-Ortiz M, Martínez-Abundis E, RoblesCervantes JA, Ramos-Zavala MG, Barrera-Durán C, González-Canudas J. Effect of metformin glycinate on glycated hemoglobin $\mathrm{A} 1 \mathrm{C}$ concentration and insulin sensitivity in drug-naive adult patients with type 2 diabetes mellitus. Diabetes Technol Ther 2014;14:1140-4. 